
\title{
typhoid fever
}

An adolescent with multi-organ involvement from

\section{Mercy Kumwenda ${ }^{1}$, Pui-Ying Iroh Tam ${ }^{1,2,3}$}

1. University of Malawi College of Medicine, Blantyre, Malawi

2. Malawi-Liverpool Wellcome Trust Clinical Research Programme, Blantyre, Malawi

3. Liverpool School of Tropical Medicine, Liverpool, UK

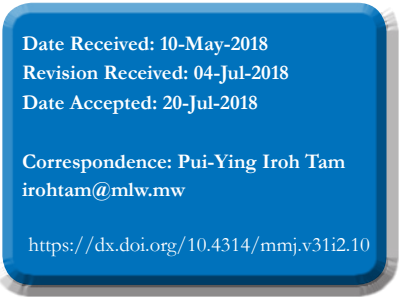

Typhoid fever is usually a mild clinical disease, but it can have potentially serious complications. Here, we describe a case of an adolescent male who presented with severe illness and multi-organ involvement from typhoid fever. He required follow-up after discharge but eventually recovered. Clinicians should be aware of the spectrum of clinical manifestations as early recognition will improve monitoring and management of typhoid disease.

Keywords: typhoid fever, enteric fever, adolescent, gastrointestinal, musculoskeletal, anemia, haematological, cardiovascular, neurological, adolescent

\section{Case presentation}

A 13-year old HIV-negative boy presented with fever and leg pains for 2 months. The leg pain radiated downwards, was associated with lower back pain, and became so severe that he was unable to walk for two weeks before presentation at hospital. After a month, he developed a cough and according to the mother he lost weight. A week before presentation, he developed lower leg swelling and then diarrhoea and vomiting two days prior. There was no history of night sweats or TB contact. He was a previously well child with normal growth and development, and no admissions or illnesses until this episode.

At admission, he had a heart rate of 170 beats per minute, respiratory rate of 28 breaths per minute, temperature of $38{ }^{\circ} \mathrm{C}$, a Glasgow Coma Score of $15 / 15$, capillary refill time $<2$ seconds, and weight of $29 \mathrm{~kg}\left(<5^{\text {th }}\right.$ centile). On examination, he was cachectic, had dry mucous membranes and conjunctival pallor but no jaundice. There were coarse crepitations in both lung fields with generalized abdominal tenderness and $2 \mathrm{~cm}$ hepatomegaly, but no rebound or guarding. He had pitting oedema from feet up to the ankles. The cardiovascular exam was normal and there was no lymphadenopathy. Although he was unable to sit up or walk, there was no tenderness on palpation of the spine and he had good range of motion in the legs. Bowel and bladder function was intact and neurological exam was grossly normal.

Full blood count (FBC) revealed white blood cells (WBC) of $2.7 \times 10^{3} / \mathrm{uL}$ (neutrophils 79.4\%, lymphocytes $14.7 \%$ ), haemoglobin $(\mathrm{Hb}) 5.7 \mathrm{~g} / \mathrm{dL}$, mean corpuscular volume (MCV) $79.7 \mathrm{fl}$ and platelets (Plt) $82 \times 10^{3} / \mathrm{uL}$. The chest $\mathrm{x}$-ray showed bilateral patchy opacifications in the lungs but the thoracolumbar spine $\mathrm{x}$-rays were normal. Urea was 21.2 $\mathrm{mg} / \mathrm{dL}$ and creatinine was $0.97 \mathrm{mg} / \mathrm{dL}$. Peripheral blood film showed no candidate lymphoblasts. He was started on ceftriaxone $50 \mathrm{mg} / \mathrm{kg}$ IV once daily.

On the third day of admission, he developed neck pain and confusion and became Kernig's sign positive. He was then moved to the high dependency unit and the ceftriaxone dose was increased to meningitis dosing at $100 \mathrm{mg} / \mathrm{kg}$ once daily.
A lumbar puncture was done which showed WBC 2, RBC 6, with no organisms on Gram stain and no growth on culture. On fourth hospital day, the blood culture grew Salmonella Typhi, which was subsequently found to be susceptible to ceftriaxone. Between days 5 and 8 , he was found to be hypotensive with blood pressures ranging from 64 to 80 (systolic)/38-40 (diastolic) $\mathrm{mmHg}$. He was given a bolus of IV fluids and kept on maintenance fluids to maintain the blood pressure above 90/60 mmHg. The fever resolved by day 5 , confusion by day 6 and the cough by day 7; however, his back and leg pain persisted even until time of discharge. On day 8 an FBC was repeated, which showed a WBC of $2.7 \times 10^{3} / \mathrm{uL}$, Hb $5.6 \mathrm{~g} / \mathrm{dL}$ and Plt of $133 \times 10^{3} / \mathrm{uL}$. He was transfused with $10 \mathrm{~mL} / \mathrm{kg}$ of packed red blood cells. The blood pressure normalized on day 10 to $96 / 70 \mathrm{mmHg}$ and he was discharged on day 11 after completing 10 days of intravenous ceftriaxone treatment.

On follow up in general clinic a week post-discharge, his blood pressure was 101/69 $\mathrm{mmHg}$, and he was regaining strength in his legs and was able to walk with minimal support. The FBC had improved with WBC 3.6x10 $3 / \mathrm{uL}, \mathrm{Hb}$ $9.9 \mathrm{~g} / \mathrm{dL}$ and Plt $446 \times 10^{3} / \mathrm{uL}$. A month post discharge, he had regained weight and was $34 \mathrm{~kg}$ ( $5^{\text {th }}$ centile), blood pressure was $115 / 73 \mathrm{mmHg}$ and the $\mathrm{FBC}$ was within normal parameters (WBC 7.3×103\%uL, Hb $10.9 \mathrm{~g} / \mathrm{dL}, \mathrm{MCV} 87.4 \mathrm{fL}$ and Plt $476 \times 10^{3} / \mathrm{uL}$. He was then discharged from further follow up.

\section{Discussion}

The clinical presentation of typhoid fever varies from a mild illness with low-grade fever, malaise, and slight dry cough to a severe clinical picture with abdominal discomfort and multiple complications. ${ }^{1,2}$ The severity of infection depends on the dose and virulence of the organism, the protective effects of gastric juice, and the host's immune response. Complications of typhoid fever occur in up to $10 \%$ of patients. ${ }^{1}$ These complications can include almost all systems of the body including central nervous system, cardiovascular, respiratory, bone and joint, haematologic, hepatobiliary, genitourinary and skin and soft tissue (Table 1). 
Table 1: Complications of typhoid fever

\begin{tabular}{|l|l|}
\hline Organ involved & $\begin{array}{l}\text { Examples of clinical } \\
\text { manifestations }\end{array}$ \\
\hline $\begin{array}{l}\text { Central Nervous System } \\
(3-35 \%)\end{array}$ & $\begin{array}{l}\text { Encephalopathy, } \\
\text { cerebral oedema, } \\
\text { subdural empyema, } \\
\text { cerebral abscess, } \\
\text { meningitis, ventriculitis } \\
\text { seizures, psychosis }\end{array}$ \\
\hline Cardiovascular $(1-5 \%)$ & $\begin{array}{l}\text { Endocarditis, myocarditis, } \\
\text { pericarditis, arteritis, } \\
\text { congestive heart failure, } \\
\text { hypotension* }\end{array}$ \\
\hline Respiratory (1-6\%) & $\begin{array}{l}\text { Pneumonia, empyema } \\
\text { Bone and joint }(<1 \%)\end{array}$ \\
\hline $\begin{array}{l}\text { Osteomyelitis, septic } \\
\text { arthritis }\end{array}$ \\
reported) & $\begin{array}{l}\text { Haemophagocytic } \\
\text { syndrome, pancytopenia }\end{array}$ \\
\hline Hepatobiliary $(1-6 \%)$ & $\begin{array}{l}\text { Cholecystitis, hepatitis, } \\
\text { hepatic abscesses, } \\
\text { ileal perforation with } \\
\text { peritonitis, }{ }^{*} \text { paralytic ileus }\end{array}$ \\
\hline Genitourinary (<1\%) & $\begin{array}{l}\text { Urinary tract infections, } \\
\text { renal abscesses, pelvic } \\
\text { infections, testicular } \\
\text { abscesses, epididymitis }\end{array}$ \\
\hline
\end{tabular}

\section{${ }^{\star}$ Most important, life-threatening complications}

Few case reports to date have documented multiple complications of typhoid in a single patient. $^{5}$ Our case is notable in that our patient had multiple organ involvement with the Salmonella Typhi. His complications included haematologic (pancytopenia), central nervous system (confusion, meningism), respiratory (pneumonia), autonomic/cardiovascular (hypotension), and possible bone and joint (suspected vertebral osteoarthritis) involvement. While we could not definitively prove osteoarthritis as the $\mathrm{x}$-rays were normal and further imaging was not done, given that his symptoms improved after treatment, we considered that the radiating back and leg pain were likely associated with the typhoid infection. These many complications in a single patient have not yet been reported. Fortunately, while $S$. Typhi has been reported to have significant issues with antibiotic resistance, this isolate was sensitive to ceftriaxone and the patient recovered on antibiotic therapy.

Reports on typhoid cases have attributed pancytopenia to bone marrow suppression, infection-associated haemophagocytic syndrome and disseminated intravascular coagulation. ${ }^{3}$ These haematologic changes resolve with complete treatment. ${ }^{4}$ The involvement of the central nervous system varies from $10-40 \%$ and manifests as toxic confusional state $(57 \%)$, encephalopathy, meningism $(5 \%)$, meningitis $(0.2 \%)$, convulsions $(1.7 \%)$, focal neurological deficits $(0.5 \%)$, optic neuritis, sensorineural deafness $(0.5 \%)$, and peripheral neuropathy $(0.7 \%) .{ }^{5}$ Most of the neurologic complications occur during the second week but may be the initial features. ${ }^{5}$ It is thought that the typhoid bacillus quite regularly enters the lungs through the pulmonary circulation in patients with bacteremia, and Artaud in 1885 first described the possible invasion of the lungs by typhoid bacilli. ${ }^{6}$ There is little literature on the phenomenon of hypotension as a complication of typhoid fever. However, Rajoo et al reported a case of an 11-year old boy who developed transient dysautonomia and cerebellitis as complications of typhoid. He had variable pulse rates and hypotension in the erect posture, which were corrected on lying down. ${ }^{5}$ Bone and joint complications in typhoid include osteomyelitis and septic arthritis. A case has also been reported in which a patient developed pyogenic spondylodiscitis with typhoid infection that mimicked spinal tuberculosis. ${ }^{7}$

\section{Conclusion}

The learning point from this case is that although typhoid is generally a mild illness, in some circumstances it can present as a severe life-threatening illness affecting almost every system of the body. Atypical features of typhoid can mimic many other diseases. Proper identification of such complications will assist clinicians in appropriate management and supportive care of these patients while they recover from the infection.

\section{References}

1. Communicable Disease Surveillance and Response Vaccines and Biologicals. Background document: The diagnosis, treatment and prevention of typhoid fever. (C) World Health Organization 2003, WHO/ V\&B/03.07 www.who.int/vaccines-documents/ Accessed 2/8/2017.

2. Obaro SK, Iroh Tam PY, Mintz E. The unrecognized burden of typhoid disease. Expert Rev Vaccines. 2017 ;16(3):249-260. doi: 10.1080/14760584.2017.1255553.

3. Pathak R, Sharma A, Khanal A. Enteric Fever With Severe Pancytopenia in a 4 year old girl. J Nepal Med Assoc. 2010 ; 50(180):313-315.

4. James J, Dutta TK, Jayanthi S. Correlation of Clinical and Hematologic Profiles with Bone Marrow Responses in Typhoid Fever. Am J Trop Med Hyg. 1997; 57(3):313-316.

5. Thapa R, Banerjee P, Akhtar N et al. Transient Dysautonomia and Cerebellitis in Childhood Enteric Fever. J Child Neurol. 2008; 23(9):1081-2.

6. Harrington FB. The Pulmonary Complications of Typhoid Fever. Boston Med Surg J. 1886; 114:28-30. doi: 10.1056/ NEJM188601141140203

7. Barnini Banerjee et al. Typhoid Spondylodiscitis Mimicking Tuberculosis in a Teenage Girl. J Infect Public Health. 2018 Jan Feb;11(1):136-137. doi: 10.1016/j.jiph.2017.04.004. 